\title{
Sarcoma sinovial de la hipofaringe. Resección y reconstrucción con colgajo supraclavicular: reporte de caso
}

\author{
José Antonio Posada-Torres, Antonio Gómez-Pedraza, Karla Susana Martín-Tellez, Gabriel Kraus-Fishcher, \\ Daniela García-Monroy y Katia Picazo-Ferrera
}

Centro Médico ABC, Ciudad de México, México

\section{Resumen}

El sarcoma sinovial es un tumor de tejidos blandos de alto grado y extremadamente raro. Su localización cervical es poco común, por lo que representa un reto diagnóstico. Se presenta el caso de una paciente femenina de 21 años de edad con un sarcoma sinovial monofásico de la hipofaringe, que presentó disfagia y disnea como síntomas iniciales. El diagnóstico se realizó basado en la clínica, los estudios de imagen, endoscopia, biopsias y estudios de inmunohistoquímica; así como fluorescencia por sonda de hibridación in situ (FISH). Se decidió tratar con resección quirúrgica completa y se reconstruyó mediante un colgajo supraclavicular tunelizado, el cual se considera como una técnica emergente para cubrir defectos amplios en cirugías de cabeza y cuello.

Palabras clave: Sarcoma sinovial. Faringe. Hipofaringe. Resección. Reconstrucción. Colgajo supraclavicular.

\section{Synovial sarcoma of the hypopharynx. Resection and reconstruction with supraclavicular flap: case report}

\section{Abstract}

Synovial sarcoma is a rare high-grade soft tissue sarcoma, and the cervical region is an uncommon location; this makes its prompt diagnosis difficult. We present a case of a 21-year-old female patient with a monophasic synovial sarcoma arising from the hypopharynx with dyspnea and difficult swallowing. The diagnosis was supported on clinical, radiological, endoscopic studies, and surgery as well as inmmunohistochemical and fluorescence in situ hybridization. Complete resection was achieved, and a supraclavicular artery island flap was used for covering the defect; this is an emerging technique for head and neck oncologic reconstructions.

Key words: Synovial sarcoma. Pharynx. Hypopharynx. Resection. Reconstruction. Supraclavicular Flap.

\section{Correspondencia:}

K. Picazo Ferrera E-mail: kpicazo@gmail.com 1665-9201/@ 2018 Sociedad Mexicana de Oncología. Publicado por Permanyer México SA de CV. Este es un artículo Open Access bajo la licencia CC BY-NC-ND (http://creativecommons.org/licenses/by-nc-nd/4.0/).
Disponible en internet: 13-05-2019 Gac Mex Oncol. 2019;Supp 18:26-30 www.gamo-smeo.com 


\section{Introducción}

El sarcoma sinovial se denominó así debido a su semejanza histológica a las células sinoviales; sin embargo, actualmente se sabe que estos tumores no derivan de las articulaciones y su origen ha sido ampliamente investigado ${ }^{1}$. Menos del $10 \%$ de estos tumores tienen una localización intraarticular².

El primer sarcoma sinovial de faringe fue descrito por Jernstrom en $1954^{3}$. Este tumor mesenquimatoso es altamente agresivo y afecta predominantemente a pacientes jóvenes, con una mortalidad del $50 \%$ a cinco años. Existe una mayor incidencia en el sexo masculino, con una relación 2:14.

Existen dos subtipos histológicos, el sarcoma sinovial monofásico y el bifásico. El sarcoma sinovial bifásico presenta componentes fusiformes y epiteliales, mientras que los sarcomas monofásicos contienen células fusiformes únicamente ${ }^{5}$.

Los monofásicos son el subtipo de sarcoma sinovial más común ${ }^{5}$. Se presentan clínicamente como tumores de tejidos blandos en las extremidades en pacientes jóvenes, pero hasta el $10 \%$ pueden aparecer en cabeza y cuello ${ }^{6,7}$. Este tipo de sarcomas generalmente se desarrollan del tejido conectivo localizado en la región paravertebral y se presentan como tumoraciones retro o parafaríngeas ${ }^{5}$. El tratamiento de elección es la resección con o sin quimioterapia o radioterapia. No existen estudios prospectivos o aleatorizados, por lo que las recomendaciones del tratamiento se basan en resultados obtenidos de estudios de sarcomas en extremidades ${ }^{8-10}$.

En este artículo presentamos un caso de sarcoma sinovial monofásico dependiente de la pared posterior de la hipofaringe que se resecó en su totalidad y se reconstruyó con un colgajo fasciocutáneo en isla de la arteria supraclavicular, técnica de reconstrucción poco frecuente.

\section{Reporte del caso}

Presentamos el caso de una paciente femenina de 20 años de edad, quien inicia su padecimiento actual con disfagia a sólidos y a líquidos, acompañada de disnea de 12 meses de evolución, motivo por el cual acude a valoración. La sintomatología fue progresiva hasta una obstrucción completa de la vía aérea. Se realizó una tomografía, la cual mostró una masa heterogénea de $4.9 \times 2.7 \mathrm{~cm}$ en la parte inferior izquierda del espacio parafaríngeo y con reforzamiento a la administración de contraste, con compresión extrínseca

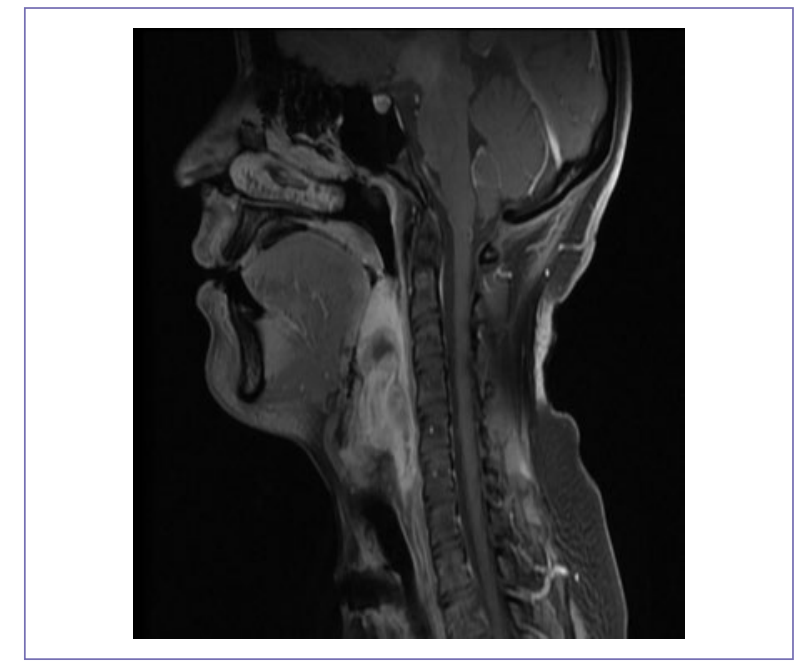

Figura 1. Imagen de resonancia magnética, corte sagital.

del $90 \%$ de la luz de la vía aérea. A la vista de estos hallazgos, se realizó una traqueostomía de forma urgente. Posteriormente una gastroscopia mostró una masa de aspecto quístico y sólido con áreas de necrosis en la hipofaringe, se tomaron biopsias y se realizó una gastrostomía percutánea. El resultado de las biopsias mostró una proliferación de células linfoides atípicas, con tejido positivo para CD20+ y BCL-2, sin lograr determinar un diagnóstico definitivo. A la exploración física la paciente se encontraba estable, a la palpación con una masa bien circunscrita de aproximadamente 6 $x 4 \mathrm{~cm}$ en la región lateral izquierda del cuello y con dificultad para la apertura bucal completa.

Se realizó una resonancia magnética de complemento, confirmando la presencia de una lesión de 7.3 x 3.8x $2.7 \mathrm{~cm}$ localizada en la retrofaringe con extensión hacia el paladar blando y la hipofaringe. Esta masa se mostraba hipointensa en la secuencia T1, además de observar linfadenopatías cervicales en los niveles IIA y III. (Fig. 1)

De acuerdo a la exploración física, los hallazgos histopatológicos previos y los resultados de los estudios de imagen; se decidió realizar una biopsia excisional con la que se concluye el diagnostico de sarcoma sinovial monofásico de alto grado. Se realizó FISH para el gen SYT usando una sonda de color dual, comprobando la existencia de la traslocación entre los genes SYT (18q11.2) y SSx (x:18) (p11.2;q11.2) (Fig. 2).

Previo a la cirugía se realizó un rastreo de los vasos supraclaviculares mediante ultrasonido Doppler. Se llevó a cabo, una incisión transcervical desde la región mastoidea hasta el hueso hioides. Se realizó una 


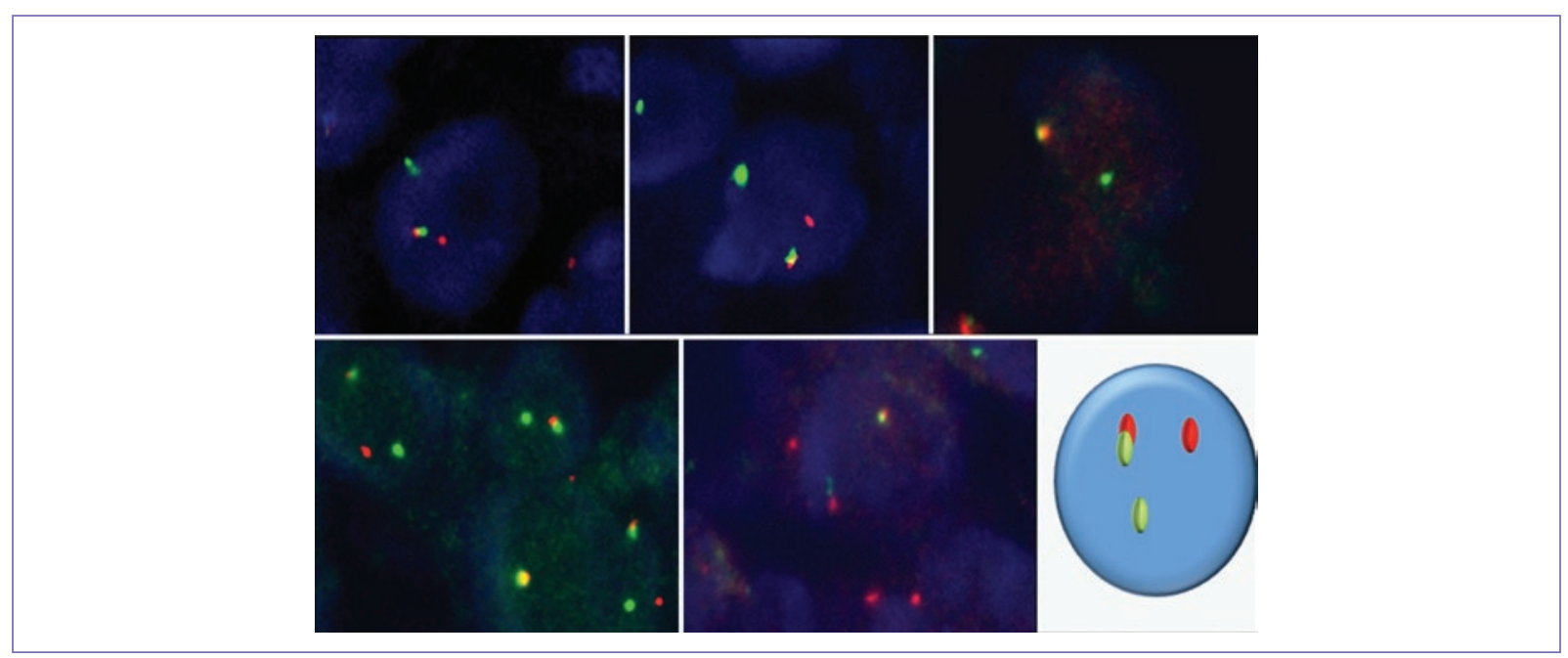

Figura 2. Traslocación entre los genes SYT (18q11.2) y SSx (x:18) por FISH.

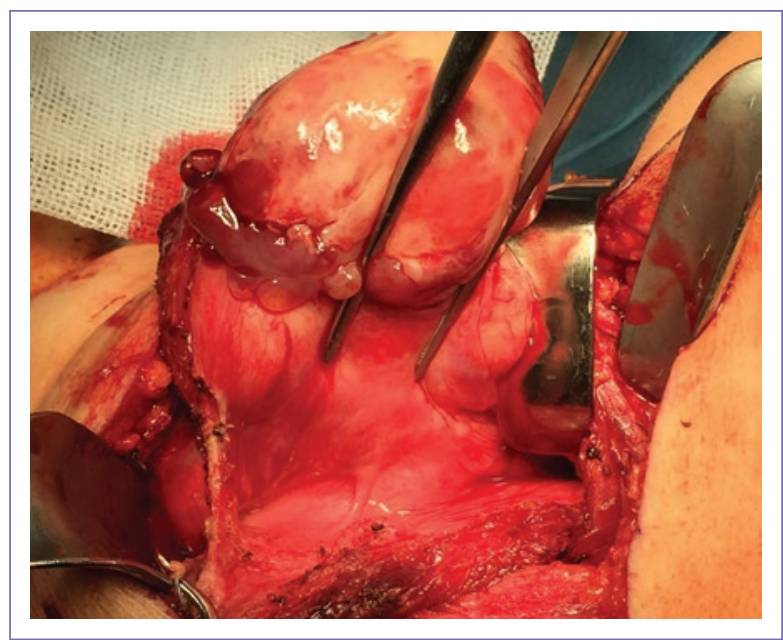

Figura 3. Faringotomía lateral.

faringotomía lateral para acceder al tumor, el cual estaba adherido a la pared y al seno piriforme. Se resecó de forma total la pieza (Fig.3), se envió para estudio transoperatorio el cual fue negativo para células neoplásicas en los márgenes.

Nuevamente, mediante ultrasonido Doppler se ubicó la arteria supraclavicular dentro del triángulo formado por la clavícula, el borde posterior del esternocleidomastoideo y la vena yugular. Se creó un colgajo distal de espesor total de $7 \mathrm{~cm}$, incluyendo la fascia; se tunelizó por debajo del musculo esternocleidomastoideo y se desepitelizó la porción proximal. La piel del sitio donador se aproximó de forma primaria, así como la incisión cervical. Se decidió realizar la reconstrucción

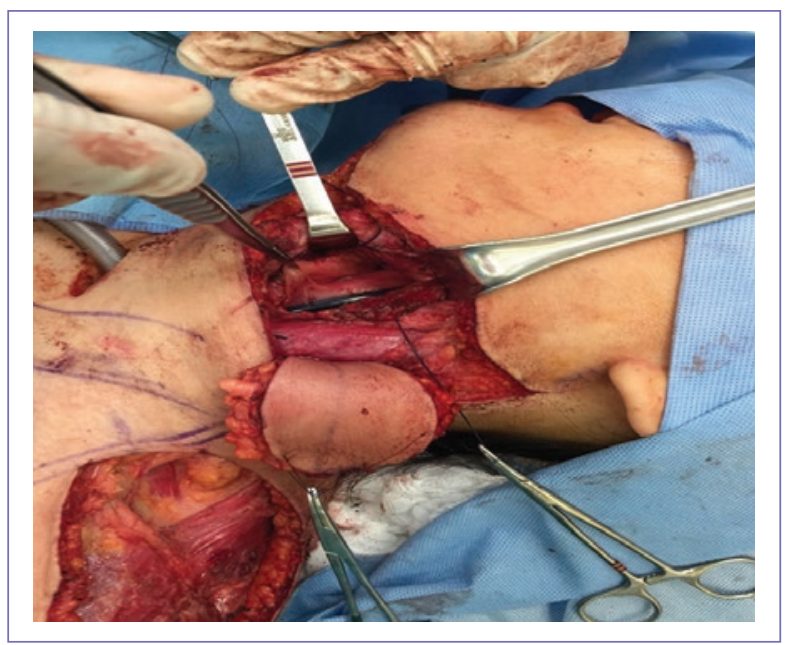

Figura 4. Colgajo supraclavicular tunelizado.

con este colgajo debido a los excelentes resultados estéticos, funcionales y anatómicos (Fig. 4).

El resultado histopatológico final mostró células en huso y confirmó el diagnóstico de sarcoma sinovial monofásico de alto grado. Las pruebas inmunohistoquímicas fueron positivas para los receptores TLE-1, CD99, CD56 y BCL-2; el 25\% de las células neoplásicas fueron positivas para Ki67 (Fig. 5). No se observó invasión vascular ni linfática y los márgenes quirúrgicos fueron negativos para neoplasia en el reporte definitivo (Fig. 6). La paciente cursó con adecuada evolución, sin embargo, en el décimo día postoperatorio presentó un episodio de broncoaspiración documentado durante una serie esofagogastroduodenal de control. Por lo 


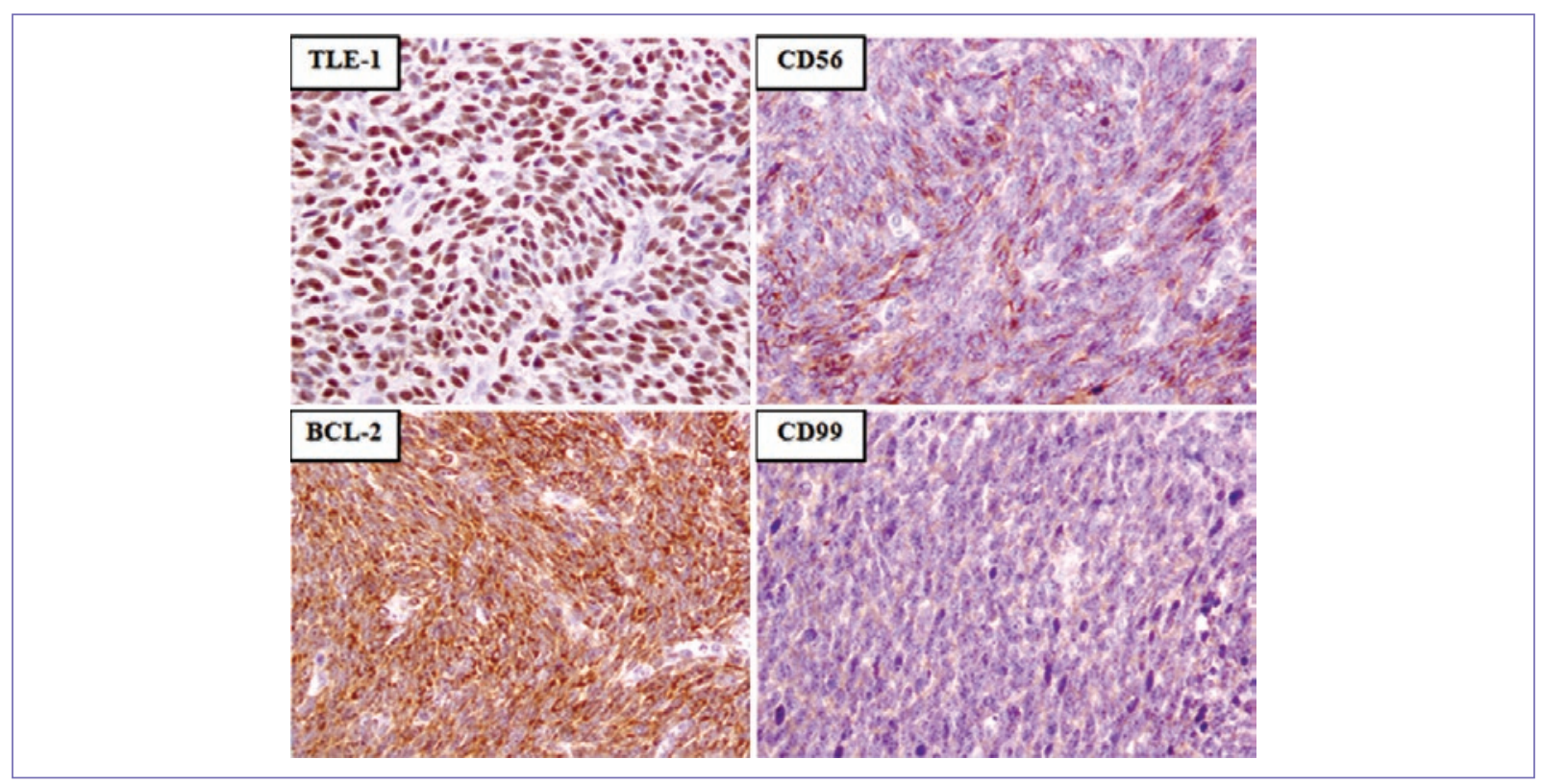

Figura 5. Pruebas de inmunohistoquímica.

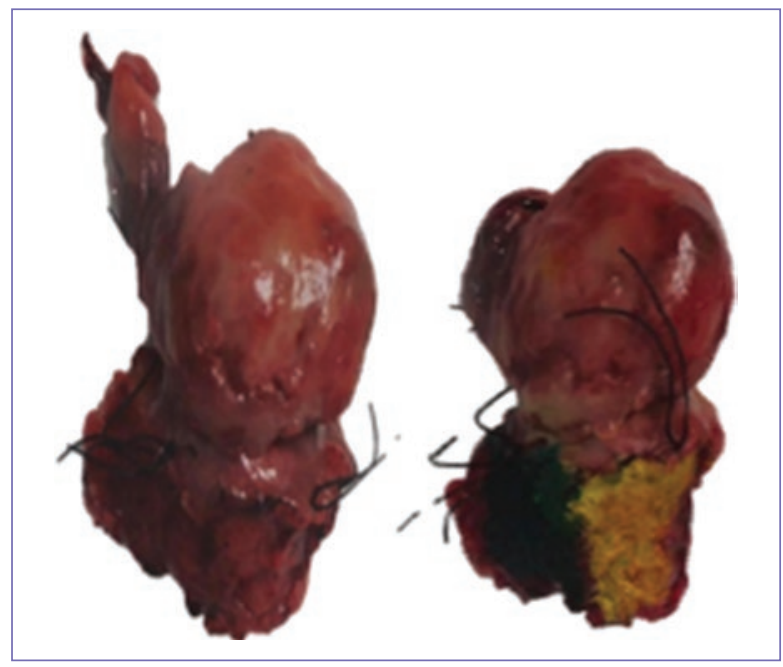

Figura 6. Imagen macroscópica del tumor resecado.

anterior, se decidió iniciar nutrición enteral mediante gastrostomía percutánea hasta que la paciente fuera capaz de deglutir sin complicaciones.

Seis semanas después de la cirugía se inició el primer ciclo de quimioterapia a base de adriamicina e ifosfamida. En la octava semana postoperatoria se decidió iniciar radioterapia adyuvante. Seis meses después, la paciente continúa con la cánula de traqueostomía funcional y la gastrostomía de protección hasta que el tratamiento oncológico concluya.

\section{Discusión}

A pesar de su nombre, los sarcomas sinoviales raramente se originan en la membrana sinovial, pero la localización más frecuente es en sitios alrededor de las grandes articulaciones ${ }^{11}$. No existe sintomatología típica de estos tumores y el diagnóstico se basa en los resultados histopatológicos, así como en los exámenes citogenéticos; otras pruebas como la FISH y la reacción en cadena de la polimerasa con transcriptasa inversa (RTPCR) se pueden utilizar para detectar translocaciones cromosómicas que apoyen el diagnóstico final' ${ }^{12,13}$. El tratamiento de elección es la resección quirúrgica completa y agresiva de este tipo de tumores, ya que los márgenes quirúrgicos negativos impactan directamente en la supervivencia y el pronóstico de la enfermedad ${ }^{14}$. El tratamiento con quimioterapia y radioterapia adyuvante sigue siendo controvertido en la actualidad ${ }^{15}$. Debido a las grandes resecciones que se tienen que realizar en estos pacientes, especialmente cuando los tumores se localizan en la región cervical, pueden tener efectos estéticos y funcionales terribles. Por lo anterior, se utilizan diferentes técnicas de reconstrucción y creemos que un colgajo pediculado y tunelizado como el que se realizó en este caso es el de mejor pronóstico y resultado estético. La reconstrucción de la faringe y el esófago cervical después de la resección de estos tumores representa un reto para el cirujano. Generalmente se cubre con transferencia de tejido sano o colgajos libres, 
aunque estos últimos tienen un riesgo de necrosis de hasta el $10 \%$. Por ello una buena alternativa es utilizar los colgajos tunelizados.

En el caso de este paciente en particular, se eligió un colgajo supraclavicular tunelizado como una técnica poco frecuente y novedosa. Este tipo de colgajos ofrecen excelentes resultados anatómicos, estéticos y funcionales en defectos amplios. El uso de colgajos regionales, especialmente para reconstruir defectos en cabeza y cuello, disminuye el riesgo de necrosis y otras complicaciones cuando se lo compara con el empleo de colgajos libres ${ }^{16,17}$.

\section{Conclusiones}

En conclusión, los sarcomas de tejidos blandos son una entidad poco frecuente. Los sarcomas sinoviales de la faringe representan una localización extremadamente rara para estos tumores.

El diagnóstico se debe de basar en los hallazgos radiológicos e histopatológicos. El pilar del tratamiento es la cirugía, con una resección completa de estos tumores para lograr un control local de la enfermedad. La reconstrucción con un colgajo supraclavicular tunelizado es una técnica novedosa y reproducible para cubrir defectos causados por resecciones oncológicas en cabeza y cuello. Los sitios donadores más frecuentes para realizar un colgajo tunelizado en este tipo de reconstrucciones son la región posterior o la anterior del tórax.

Aunque sigue siendo motivo de controversia, el tratamiento adyuvante se debe de iniciar tan pronto como se pueda. Es importante involucrar un equipo multidisciplinario que incluya un cirujano de cabeza y cuello. El diagnóstico temprano y el tratamiento oportuno son los factores que más influyen en el pronóstico de estos pacientes.

\section{Conflicto de intereses}

Los autores de este trabajo declaran no tener conflictos de intereses para la elaboración de este artículo.

\section{Bibliografía}

1. Alotaibi N, Bornand A, Dulguerov N, Becker M, Dulguerov P. Synovial sarcoma of the hypopharynx in a pediatric patient: Case report. Int J Surg Case Rep. 2016;28:1-3.

2. Betal D, Babu R, Mehmet V. Monophasic synovial sarcoma of the pharynx: a case report. Int Semin Surg Oncol. 2009;6:9.

3. Jernstrom P. Synovial sarcoma of the pharynx: report of a case. Am J Clin Pathol. 1954;24:957-961.

4. Jamshed A, Loya A, Tirmizi AH, Hussain R. Synovial sarcoma of the hypopharynx. Int J Head Neck Surg. 2013;4:86-8.

5. Osma U, Eyigor H, Suren D, Sezer C, Yilmaz MD. Biphasic synovial sarcoma of the hypopharynx. Ear Nose Throat J. 2015;94(4-5):E36-9.

6. Weiss SW, Goldblum JR. Enzinger and Weiss's soft tissue tumors. $6^{\text {th }}$ ed. Philadelphia: Mosby Elsevier; 2013.

7. Agarwal M, Singh A, Abrari A, Singh N. Monophasic synovial sarcoma of posterior pharyngeal wall: a rare case report with unique reconstruction using lateral trapezius flap. Eur Arch Otorhinolaryngol. 2017; 274(4):2059-64.

8. Haldar M, Randall RL, Capecchi MR. Synovial sarcoma: from genetics to genetic-based animal modeling. Clin Orthop Relat Res. 2008; 466(9):2156-67.

9. Roeder F. Neoadjuvant/adjuvant radiation therapy in soft tissue sarcomas. Journal Onkologie. 2015;1:41-50.

10. Mullen JR, Zagars GK. Synovial sarcoma outcome following conservation surgery and radiotherapy. Radiother Oncol. 1994;33(1):23-30.

11. Kartha SS, Bumpous JM. Synovial sarcoma: diagnosis, treatment, and outcomes. Laryngoscope. 2002;112:1979-82.

12. Amble FR, Olsen KD, Nascimento AG, Foote RL. Head and neck synovial cell sarcoma. Otolaryngol Head Neck Surg. 1992;107(5):631-7.

13. Tvrdík D, Povýsil C, Svatosová J, Dundr P. Molecular diagnosis of synovial sarcoma: RT-PCR detection of SYT-SSX1/2 fusion transcripts in paraffin- embedded tissue. Med Sci Monit. 2005;11(3):MT1-7.

14. Ladanyi M. Correlates of SYT-SSX fusion type in synovial sarcoma: Getting more complex but also more interesting? J Clin Oncol. 2005; 23(15):3638-9.

15. Oliveira AM, Fletcher $C D$. Molecular prognostication for soft tissue sarcomas: Are we ready yet? J Clin Oncol. 2004;22(20):4031-4

16. Crowson MG, Lalich I, Keeney MG, Garcia JJ, Price DL. Clinicopathologic factors and adjuvant treatment effects on survival in adult head and neck synovial cell sarcoma. Head Neck. 2015;37(3):375-80.

17. Pallua N, Magnus Noah E. The tunneled supraclavicular island flap: an optimized technique for head and neck reconstruction. Plast Reconstr Surg. 2000;105(3):842-51; discussion 852-4. 